\section{Commentary: Do the right thing, even if no one is watching, consider Jeffersonian as well as Kennedyism}

\author{
Robert J. Cerfolio, MD, MBA, FACS, FCCP
}

Lazzaro and colleagues ${ }^{1}$ have written an interesting article and applied a famous quote from our 35th President of the United States, John F. Kennedy. The authors appropriately asked us to do a better job for our patients with lung cancer. Perhaps a quote from the third President of the United States, Thomas Jefferson is more fitting:

\section{"Whenever you do a thing, act as if the world were watching."}

Removing or at least sampling multiple lymph node stations of mediastinal (N2) and hilar (N1) nodes during a lung cancer operation is the right thing to do. Yet, the data suggest we as a group continue to fail to do it and in turn fail our patients. ${ }^{2}$ The presence or absence of an audience should not be a variable that steers our moral compass toward or away from doing the right thing. However, this latter clause is never truer than as a caregiver or a physician. This was our pledge. It was our promise when we rose, raised our right hand, and repeated the powerful words to honor the Hippocratic Oath. It is incumbent on us and is at the very least we should do. No one is more vulnerable than when a patient in the operating room: naked, paralyzed, and trusting. If we can't do the right thing there, then when can we?

From the Department of Cardiothoracic Surgery, New York University Langone Health, New York, NY.

Disclosures: Dr Cerfolio discloses past relationships with AstraZeneca, Bard Davol, Bovie Medical Corporation, C-SATS, ConMed, Covidien/Medtronic, Ethicon, Fruit Street Health, Google/Verb Surgical, Intuitive Surgical, KCI/Acelity, Myriad Genetics, Neomend, Pinnacle Biologics, ROLO-7, Tego, and TransEnterix but has none over the past 15 months.

Received for publication Nov 9, 2019; revisions received Nov 9, 2019; accepted for publication Nov 17, 2019; available ahead of print Jan 9, 2020.

Address for reprints: Robert J. Cerfolio, MD, MBA, FACS, FCCP, Department of Cardiothoracic Surgery, NYU Langone Health, 530 1st Ave, Suite 9V, New

York, NY 10016 (E-mail: robert.cerfolio@nyulangone.org).

JTCVS Techniques 2020;1:117-8

2666-2507

Copyright (c) 2019 The Author(s). Published by Elsevier Inc. on behalf of The American Association for Thoracic Surgery. This is an open access article under the CC BY-NC-ND license (http://creativecommons.org/licenses/by-nc-nd/4.0/).

https://doi.org/10.1016/j.xjtc.2019.11.005

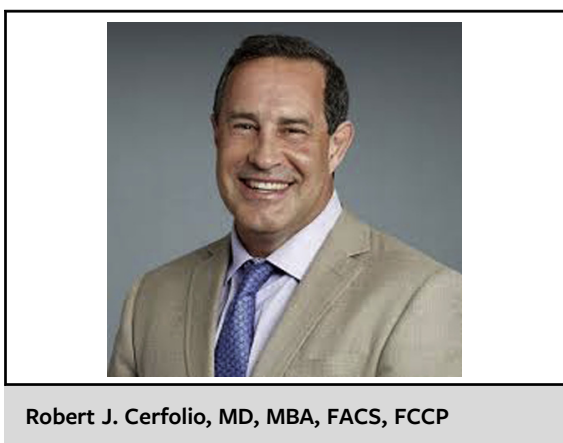

CENTRAL MESSAGE

All patients deserve high-quality lung cancer surgery-make the outcomes and metrics transparent to all.

Lymph node removal is the right thing to do during lung cancer surgery. It is a surrogate for quality. Further, it separates many of the advantages of surgical resection when compared with non-resectional forms of therapy for nonsmall cell lung cancer. Shortcuts here can be easily hidden in the operating room and when done are shameful and just lazy.

When Jefferson espoused his famous aforementioned words, he had no idea that today literally the world is watching. Everything we do is recorded. There are video cameras mounted on every street corner, smart phones tucked in every pocket, and Google and Alexa devices perched on every desktop. All we say and do is recorded and can be rewatched again and again. Although this should not be the driver that steers us toward doing the right thing, it may. The optimal operative record is the video and audio of the entire operation. Pilots have a black box-why don't we of our surgical cockpit? It would be the best proof of a quality operation if we did one, and soon it will be. However, what can we do until then to prevent our patient's care to be so susceptible to the vagaries of their surgeon's desire to "do the right thing when no one is looking?" The main import of this editorial is to offer action not just platitudes. So, we offer a plan.

\section{THE PLAN TO INCREASE MINIMALLY INVASIVE RESECTION RATES AND BETTER LYMPH NODE DISSECTION}

Let us create a national database for lung cancer resection as we have done for transplantation. Metrics of quality are shown publicly and in real time. If any, yes any, pulmonary or bronchial resection is planned and it is not 
scheduled to be performed via a minimally invasive platform, it is immediately posted and listed along with the patient's pertinent history and images. All other boardcertified general thoracic surgeons in that zip code and/ or payer's network get immediate real-time updated daily information by e-mail. They are able to communicate with the primary listing surgeon and offer to do the operation via a minimally invasive platform. If the patient is referred to a different system, the referring MD is given credit, not money. He or she has the option of accompanying the patient and watching and/or scrubbing in as well. The leads to the development of the obvious, a national license to practice medicine, not the mercantile state-type system we currently have (for example, you don't have to get out of your car and start walking just because you crossed a state line). Obviously, surgeons will game the system by scheduling every case with a video-assisted thorascopic or robotic platform, but their history will also be measured as well as their conversion rate via integrated Society of Thoracic Surgeons database and electronic healthcare systems. As in transplant data, coordinators will help prevent gaming. What about the learning curve? Our patients today can't afford their surgeons to be on one. The truth is it is a different time than just 10 years ago. Given the current widespread source of online videos, simulators, teaching courses, and regional and local expertise in each state in our unions all patients, the indigent and the remote can receive a high-quality cancer operation. Don't they deserve one?

To ensure adequate lymph node, the ideal system is that every surgeon is mandated to supply videos of all of their lymph node dissections on every cancer operation they perform. If the easily set metrics are not met, surgeons cannot charge nor collect their full remittance. This would quickly improve our patients' care. The naysayers will read and cry this is naive-too hard, too expensive, and not possible. We have all heard this before. We are already doing this is an integrated healthcare system here at NYU Langone Health using the efficiency quality index metric) that we have previously described at length. The efficiency quality index allows the performer of any commonly and repeatedly performed task (which applies to what most all of us do every day), be it making a bed or cleaning a room or performing a very specific operation such as a pulmonary lobectomy to be compared. We ask the participants of the task (not administrators) to determine what they think are fair and measurable metrics of quality, to view and ensure their data are accurate, and then vet their data with the other participants and iterate the rules of the game quarter after quarter as they see fit to achieve fairness in measuring the best from the rest. This is transparency at is best, eliminates ego from quality, and ensures the whole world is watching. Thus, we purport, it is not Kennedyism that we should apply, but rather Jeffersonian.

\section{References}

1. Lazzaro RS, Patton BP. Applying "Kennedyism" to lung cancer treatment; let's take more nodes. J Thorac Cardiovasc Surg Tech. 2020;1:114-6.

2. Little AG, Rusch VW, Bonner JA, Gaspar LE, Green MR, Webb WR, et al. Patterns of surgical care in lung cancer patients. Ann Thorac Surg. 2005;80: 2051-6. 